\title{
The Relationship Between Alexithymia and Coping Styles: The Mediator Roles of Anger and Anger Expression Styles
}

Bukre KAHRAMANOL ${ }^{*}$, Ihsan DAG

${ }^{*}$ Hacettepe University, Department of Psychology, Ankara, Turkey
Contact Information:

bukrekahramanol@gmail.com

\section{Introduction}

The concept of alexithymia includes characteristics such as difficulties in identifying feelings and distinguishing between feelings and bodily sensations created by emotional arousal, problems expressing feelings to other people, constricted imaginal processes manifesting themselves in limitation of fantasies, and a stimulus-bound, externally-oriented cognitive structure (Taylor, Bagby, \& Parker, 1997). Alexithymic characteristics were generally found to be associated with trait anger, anger-in and anger-control (Conrad, Geiser, Haidl, Hutmacher, Liedtke, \& Wermter, 2008). It was also found that alexithymia was linked to maladaptive coping strategies (Besharat, 2010; Tominaga, Choi, Nagoshi, Wada, \& Fukui, 2014; Velasco, Fernandez, Paez, \& Campos, 2006). In addition to these findings, numerous researchers have assumed specific associations between types of negative emotions and the choice of coping strategies. Although, the link between anger expression and coping styles has received less attention, there are strong reasons to assume that individuals differing in anger expression will also differ in their coping patterns (Diong \& Bishop, 1999). In the majority of research with different samples, it was found that trait anger (Maxwell \& Siu, 2008; Myers, Fleming, Lancman, Perrine, \& Lancman, 2013) and anger-out (Diong \& Bishop, 1999; Diong et al., 2005; Ferrer et al., 2010) were negatively associated with problem-focused coping styles and positively associated with emotion-focused coping styles. On the contrary, anger-control was found to be positively related to problemfocused coping styles and negatively related to emotion-focused coping styles (Diong et al., 2005)

To sum, the purpose of current research is to investigate the mediating roles of anger and anger expression styles in the relationship between alexithymia and coping styles in an university sample.

\section{Method}

Participants: This research compromised of 434 college students (244 women, 190 men) from different departments of Hacettepe University. The mean age was 20.55 (SD = 1.76). Instruments: Demographic Information Form, 20-item Toronto Alexithymia Scale (Bagby, Taylor, \& Parker, 1994; Bagby, Parker, \& Taylor, 1994), State-Trait Anger Expression Inventory (Spielberger, Jacobs, Russel, \& Crane, 1983), Ways of Coping Questionnaire (Folkman \& Lazarus (1980). The Turkish adaptation studies showed that all of the instruments used in the study have psychometric validity and reliability.

Statistical Analyses: The hypothesized model was tested by the PROCESS macro available for SPSS with 5000 bootstrap samples (Hayes, 2013).

\section{Problem-Focused Coping Styles} Optimistic Self-Confident

Seeking for Social Support

\section{Emotion-Focused Coping Styles} Helpless Submissive

\section{Results and Discussion}

$>$ The total model was significant and explained $\% 37$ of variance in problem-focused coping styles, $F(5,428)=23.06, p<.001$ and $\% 21$ of variance in emotion-focused coping styles, $F(5$, $428)=50.67, p<.001$.

$>$ The results indicated that anger-in and anger-control had significant mediator roles on the relationship between alexithymia and problem-focused/emotion-focused coping styles.
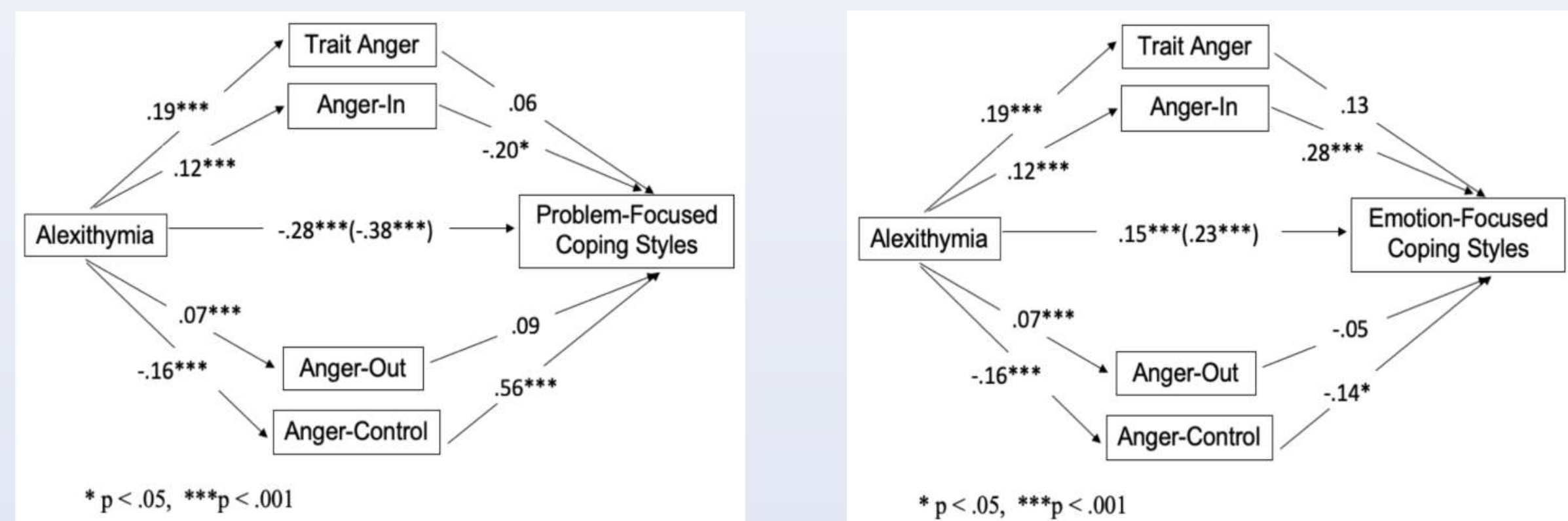

Figure 1. \& 2. Unstandardized Coefficients for the Mediator Role of Anger and Anger Expression Styles

Current study emphasizes that the benefit of addressing alexithymic characteristics, the frequency of anger experience, and healthy ways of anger expression simultaneously and as a whole in psychotherapies aiming to strengthen the ways of coping with stress. Emotion regulation and anger management skills can be improved by some components added to the psychotherapies. Future research should focus on the bidirectional relationship between emotions and coping styles and conduct analyses with sub-dimensions of alexithymia and coping styles.

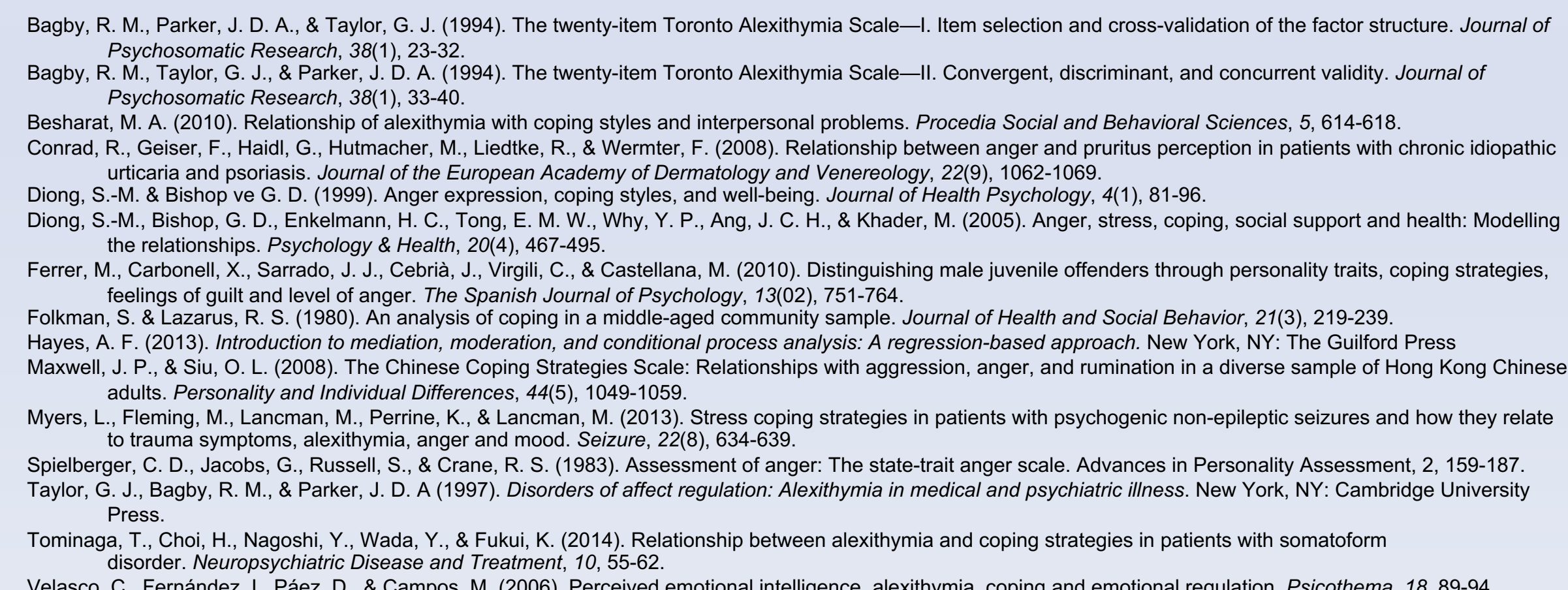

